\title{
Orthogonal Test for the Structure Parameters of Long Raster Engraving Air-Floating Platform
}

\author{
Deyun MO*, Ping MA**, Haishan LIAN***, Manfeng GONG**** \\ *Department of Electrical and Mechanical Engineering, Lingnan Normal University, Zhanjiang, China, \\ E-mail:dewin_mo@163.com \\ **Department of Electrical and Mechanical Engineering, Guangdong University of Technology, Guangzhou, China, \\ E-mail: pingma@gdut.edu.cn \\ ***Department of Electrical and Mechanical Engineering, Lingnan Normal University, Zhanjiang, China, \\ E-mail: hssmy1985@163.com \\ ****Department of Electrical and Mechanical Engineering, Lingnan Normal University, Zhanjiang, China, \\ E-mail: 576765637@qq.com
}

cross'ref http://dx.doi.org/10.5755/j01.mech.26.1.23332

\section{Introduction}

The precision air-floating platform is widely applied in the fields of lithography and precision measurement. It consists of aerostatic air-floating guideway and linear motor drive, which is connected by non-mechanical method to efficiently avoid the vibration disturbance from external environment and free from the friction, heat, wear, lubrication caused by traditional bearings [1-2]. Recently, three major international lithography equipment producers adopt air-floating platform as their core subsystem, such as, air flotation bearing support used by ASML company from Holland to realize high speed and large range motion on the horizontal plane, symmetrical aerostatic guideway driving technology used by Japanese Nikon and Canon company to realize nanometer scale motion on the horizontal plane [3].

This paper intends to design a $\mathrm{X}-\mathrm{Y}$ direction airfloating platform to engrave $3000 \mathrm{~mm}$ raster motherboard for 4-5 days. Thus loading capacity and gas consumption for airfloating guideway are key indicators, which the platform runs smoothly depends on the load capacity, and the production cost depends on the gas consumption capacity during continuous operation for a long time. Therefore, in order to meet the requirements of long raster engraving, it is greatly necessary to optimize the platform structural parameters when the form of air-floating platform is determined.

The influence of the dimension and quantity of the restrictors on the air bearing performance by establishing finite element models are studied [4-5]. Du, et al [6], and Kassab, et al [7], investigated the influence of the size and position of the equalization groove, the thickness of gas film and the pressure of gas supply pressure on the loading capacity and stiffness of the guideway through numerical analysis and experimental study. YANG, et al [8], analyzed pressure and velocity of gas film by CFD array restrictors model, the result revealed that in a certain range loading capacity of gas film can be increasingly improved when the number of restrictors increases.

The above studies mainly focus on the influence of the restrictor structure and distribution on loading capacity. Nevertheless, the comprehensive influence of gas film thickness, the guideway width and gas supply pressure on platform performance is not mentioned in previous studies. Here, we have established an ANSYS model for long raster engraving platform. Taking loading capacity and gas consumption as in- dicators, the influence of structure parameters on the performance of the guideway was investigated by orthogonal test. It is the theoretical reference for the optimum structural design.

\section{Finite element modelling and experiment study of air-floating platform}

Precision air-floating test platform made by marble material, adopts T-typed guideway structure with length of $800 \mathrm{~mm}$, width of $680 \mathrm{~mm}$, height of $300 \mathrm{~mm}$, and weight of $197 \mathrm{~kg}$, of which the width of top air-floating face is $125 \mathrm{~mm}$, bottom $95 \mathrm{~mm}$, side $150 \mathrm{~mm}$ and on each face are eight restrictors. In order to test the loading performance of the airfloating platform, a test system is set up as shown in Fig. 1.

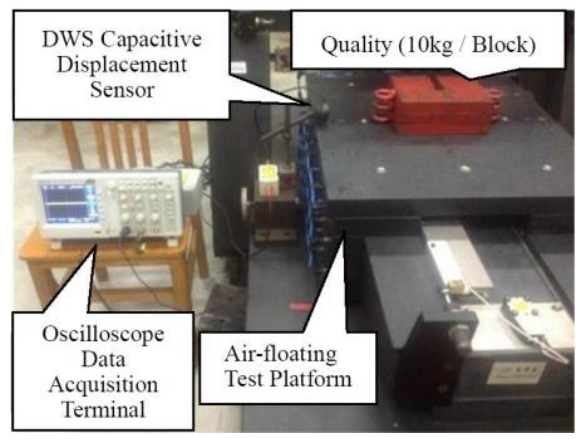

Fig. 1 Precision air-floating test platform

The test is designed for investigating the loading capacity of air-floating platform by using DWS capacitive displacement sensor with the gas supply pressure of 0.20 $\mathrm{MPa}$. During the test, at the beginning, data is collected once without air supply. Then gas is supplied for 5 minutes to ensure that the platform is fully floating and steady and measure the data at no load. After that, when the weight of the same quality ( $10 \mathrm{~kg} /$ block) is added to the platform in turn, data is recorded after each additional block until data of 60 $\mathrm{kg}$ is taken as a group. Four groups of data measured by the regression treatment is shown in Table 1.

The test data shows the air-floating is under the air supply pressure of $0.20 \mathrm{MPa}$ and the thickness of top gas film without loading is $0.0264 \mathrm{~mm}$. With the load increasing, the gap between top gas films decreases gradually. When the loading is $60 \mathrm{~kg}$, the thickness of top gas film is $0.0231 \mathrm{~mm}$ and the variation is $0.0033 \mathrm{~mm}$. 
Table 1

Results of loading performance in test

\begin{tabular}{|c|c|c|c|c|c|c|c|c|c|c|}
\hline \multirow[b]{2}{*}{$\begin{array}{l}\text { Loading capacity, } \\
\text { kg }\end{array}$} & \multicolumn{2}{|c|}{ Group 1} & \multicolumn{2}{|c|}{ Group 2} & \multicolumn{2}{|c|}{ Group 3} & \multicolumn{2}{|c|}{ Group 4} & \multirow[b]{2}{*}{$\begin{array}{l}\text { VFV, } \\
\text { V }\end{array}$} & \multirow[b]{2}{*}{$\begin{array}{l}\text { Fluctuation value of } \\
\text { top gas film, mm }\end{array}$} \\
\hline & $\begin{array}{c}\text { MV, } \\
\text { V }\end{array}$ & $\begin{array}{l}\text { VFV, } \\
\text { V }\end{array}$ & $\begin{array}{c}\text { MV, } \\
\text { V }\end{array}$ & $\begin{array}{l}\mathrm{VFV}, \\
\mathrm{V}\end{array}$ & $\begin{array}{c}\text { MV, } \\
\text { V }\end{array}$ & $\begin{array}{l}\text { VFV, } \\
\text { V }\end{array}$ & $\begin{array}{c}\text { MV, } \\
\text { V }\end{array}$ & $\begin{array}{l}\text { VFV, } \\
\text { V }\end{array}$ & & \\
\hline 0 & -5.91 & & -5.56 & & -5.34 & & -5.12 & & & \\
\hline 10 & $\begin{array}{l}-5.88 \\
\end{array}$ & -0.03 & $\begin{array}{l}-5.54 \\
\end{array}$ & -0.02 & $\begin{array}{l}-5.33 \\
\end{array}$ & $\begin{array}{l}-0.01 \\
\end{array}$ & $\begin{array}{l}-5.13 \\
\end{array}$ & 0.01 & -0.01 & -0.0001 \\
\hline 20 & -5.94 & 0.03 & -5.62 & 0.06 & -5.41 & 0.07 & -5.20 & 0.08 & 0.06 & 0.0006 \\
\hline 30 & -6.01 & 0.10 & -5.69 & 0.13 & -5.48 & 0.14 & -5.26 & 0.14 & 0.13 & 0.0012 \\
\hline 40 & -6.09 & 0.18 & -5.76 & 0.20 & -5.55 & 0.21 & -5.33 & 0.21 & 0.20 & 0.0019 \\
\hline 50 & -6.16 & 0.25 & -5.83 & 0.27 & -5.61 & 0.27 & -5.40 & 0.28 & 0.27 & 0.0026 \\
\hline 60 & -6.24 & 0.33 & -5.89 & 0.33 & -5.68 & 0.34 & -5.47 & 0.35 & 0.31 & 0.0033 \\
\hline No air supply & -8.62 & 2.71 & -8.29 & 2.73 & -8.06 & 2.72 & -7.85 & 2.73 & 2.72 & 0.0264 \\
\hline
\end{tabular}

MV - Measured Voltage, VFV - Voltage Fluctuation Value

According to the test results, 3D finite element model is established with an average thickness of gas film of $0.028 \mathrm{~mm}$, and the thickness of top gas film of $0.0264 \sim$ $0.0231 \mathrm{~mm}$. Gas pressure is applied to faces of each gas film with gas supply pressure of $0.20 \mathrm{MPa}$ at the restrictor inlet. The pressure field distribution of each face of gas film is shown in Fig. 2.

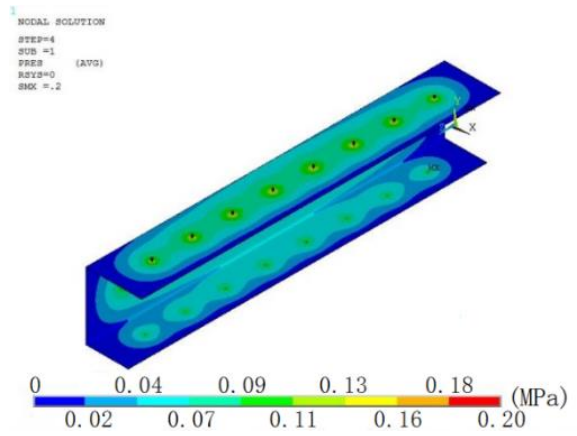

Fig. 2 The pressure field distribution of gas film

The vertical loading capacity of unilateral guideway on the vertical direction under different thickness of gas film is shown in Table 2.

Table 2

The vertical loading capacity of unilateral guideway

\begin{tabular}{|c|c|c|c|c|}
\hline \multicolumn{2}{|c|}{ Top gas film } & \multicolumn{2}{c|}{ Bottom gas film } & \multirow{2}{*}{$\begin{array}{c}\text { Vertical } \\
\text { loading } \\
\text { capacity, } \\
\mathrm{N}\end{array}$} \\
$\begin{array}{c}\text { Thickness of } \\
\text { gas film, } \\
\mathrm{mm}\end{array}$ & $\begin{array}{c}\text { Loading } \\
\text { capacity, } \\
\mathrm{N}\end{array}$ & $\begin{array}{c}\text { Thick- } \\
\text { ness of } \\
\text { gas film, } \\
\mathrm{mm}\end{array}$ & $\begin{array}{c}\text { Loading } \\
\text { capacity, } \\
\mathrm{N}\end{array}$ & \\
\hline 0.0264 & 1380.4 & 0.0296 & 400.1 & 980.3 \\
\hline 0.0259 & 1424.5 & 0.0301 & 386.6 & 1037.9 \\
\hline 0.0253 & 1471.0 & 0.0307 & 373.5 & 1097.6 \\
\hline 0.0248 & 1520.3 & 0.0312 & 361.1 & 1159.3 \\
\hline 0.0242 & 1573.2 & 0.0318 & 349.1 & 1224.1 \\
\hline 0.0237 & 1630.1 & 0.0323 & 337.8 & 1292.3 \\
\hline 0.0231 & 1689.7 & 0.0329 & 327.1 & 1362.7 \\
\hline
\end{tabular}

Through analysing the test data and results of finite element analysis, the curves of loading capacity varying with thickness of gas film are illustrated in Fig.3.

As shown in the Fig. 3, from no-load to $10 \mathrm{~kg}$, the thickness of top gas film has no significant change, and from $10 \mathrm{~kg}$ to $60 \mathrm{~kg}$, the loading capacity shows a good linear growth with the reduction of the top gas film. Comparing with the results of finite element analysis, it is found that the loading capacity varying with the change of gas film gap is the same, and the maximum deviation of loading capacity appears at thickness of $0.0231 \mathrm{~mm}$, about $6.04 \%$.

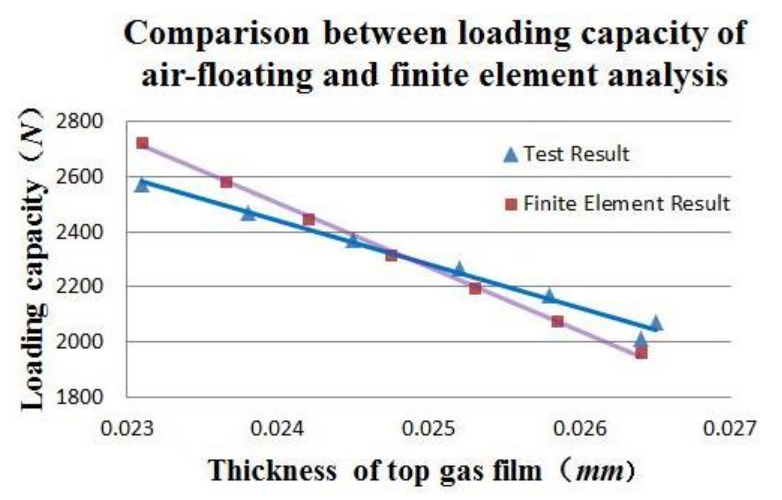

Fig. 3 Comparison between loading capacity of air-floating and finite element analysis

The deviation is due to the finite element analysis carried out under the ideal model, without considering the uneven gas film caused by external environment interference, guideway processing or assembling errors. However, the error range can meet the engineering design requirements, and the following is the modelling approach for the specific design model.

\section{Structure of long raster engraving air-floating platform and finite element modelling}

In order to satisfy the feed requirement of laser during the long raster engraving, this design adopts a symmetrical $\mathrm{X}-\mathrm{Y}$ direction air-floating platform which combines T-type guideway with dovetail guideway, shown in Fig. 4. Ones can see that $X$ direction platform not only has to support the weight of X-Y direction platform, vertical slide, laser device, and other components [9], but also overcomes overturning moment when Y direction platform is feeding [10]. Therefore, to insure the platform compact and the loading capacity enough to overcome overturning moment, $\mathrm{X}$ direction platform adopts T-type aerostatic guideway which can support the weight of $600 \mathrm{~kg}$ [11].

In practice, double row restrictors are used in end thrust plates of guideway to improve the loading capacity of guideway [12]. However, air-floating platform fixed and fed in nanometre works continuously for a few days and gas from the supply system is not so clear that air impurities would accumulate in velocity 'dead zone' between double row restrictors, the result of which finally changes the pressure field changed and affects the platform performance [13]. Hence, in order to make air-floating platform satisfy the need of long 
raster engraving, on $\mathrm{X}$ direction air-floating platform, $3 \times 3$ restrictor and grid shaped pressure groove are adopted on the top and single row restrictor and pressure groove on the side and bottom [14], as shown in Fig. 5.

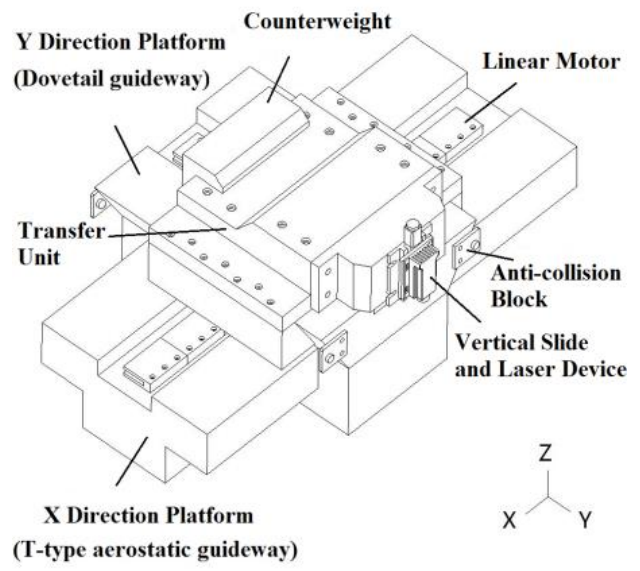

Fig. $4 \mathrm{X}$-Y direction air-floating platform

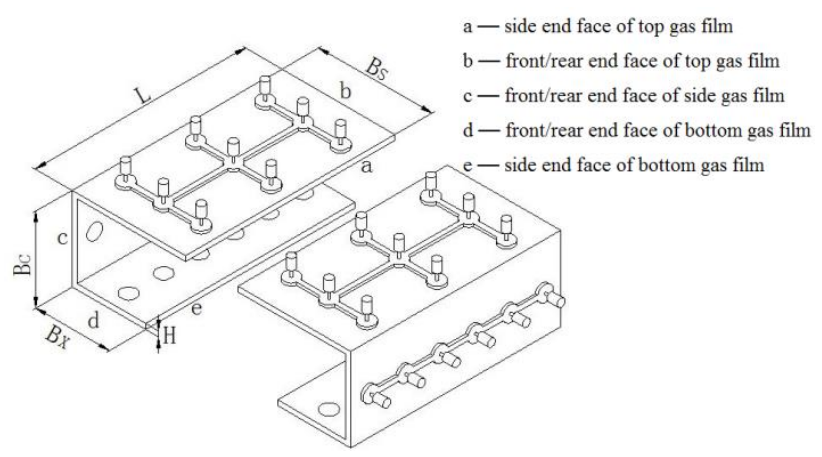

Fig. 5 Platform gas film structure

As can be seen from Fig. 5, gas films length $L=400$ $\mathrm{mm}$, top gas film width $B s=216 \mathrm{~mm}$, the number of top gas film restrictors $n=9$, side gas film width $B c=140 \mathrm{~mm}$, the number of side and bottom gas film restrictors $n=6$ [15], pressure groove is $0.05 \mathrm{~mm}$ high and $1 \mathrm{~mm}$ wide. This paper focuses on the bottom gas film width $B x$ and gas film thickness. Here each end face of gas film is numbered for the analysis of air consumption of guideway.

Due to the symmetry of guideway, gas film of left side has been chosen as the study object to establish finite element model for high solving efficiency. 3D fluid element, FLUID142, is selected to divide mapping mesh for gas film model and refine the mesh around restrictors. In addition, C1 chamfer has been built in gas film intersection.

When the platform is working, high pressure gas flows in from the roof of restrictor and throttling. Then the high pressure gas enters the guideway at subsonic speed and forms a high pressure gas film. As the gas flows toward the exhaust boundary, the aeration cross-section expands, and the gas velocity decreases. Eventually, it flows out from the end faces of the respective gas films.

The variation in fluid density and turbulent fluctuations of the high velocity gas flow is caused by the pressure gradient. Therefore, the compressibility and turbulence of the gas need to be considered when establishing the finite element model. Gas supply pressure $P s$ is applied to restrictor roof. The guideway surface and the restrictors are regarded as fixed surfaces, so each speed component is 0 , and the heat is insulated. Atmospheric pressure $\mathrm{Pa}$ that means 0 is applied to each end face of gas films. Air viscosity is $1.81 \times 10^{-5} \mathrm{~kg} /(\mathrm{ms})$ and assumed to be constant.

The Mach number at the exit of the restrictor is approximately 0.3 , which is much higher than the other positions of the gas film. Therefore, in order to ensure the calculation accuracy and high calculation efficiency, the Standard $k-\varepsilon$ turbulence model and BiCGSTAB (Bi-Conjugate Gradient Stabilized) method are selected for joint solution [16].

The standard $k$ - $\varepsilon$ turbulence model was proposed by Launder and Spalding in 1972 [17]. It is a semi-empirical model derived from turbulence theory and experimental data. It is widely used in engineering.

For compressible fluids, the transport equation of the turbulent kinetic energy $k$ and its dissipation rate $\varepsilon$ can be expressed as Eqs. (1)-(2):

$$
\begin{gathered}
\frac{\partial(\rho k)}{\partial t}+\frac{\partial\left(\rho k u_{i}\right)}{\partial x_{i}}=\frac{\partial}{\partial x_{j}}\left[\left(\mu+\frac{\mu_{t}}{\sigma_{k}}\right) \frac{\partial k}{\partial x_{j}}\right]+G_{k}-\rho \varepsilon+G_{b}-Y_{M}, \\
\frac{\partial(\rho \varepsilon)}{\partial t}+\frac{\partial\left(\rho \varepsilon u_{i}\right)}{\partial x_{i}}=\frac{\partial}{\partial x_{j}}\left[\left(\mu+\frac{\mu_{t}}{\sigma_{\varepsilon}}\right) \frac{\partial \varepsilon}{\partial x_{j}}\right]+C_{1 \varepsilon} \frac{\varepsilon}{k}\left(G_{k}+C_{3 \varepsilon} G_{b}\right)-C_{2 \varepsilon} \rho \frac{\varepsilon^{2}}{k},
\end{gathered}
$$

where $\mu$ is air viscosity, it is assumed to be a constant, $\mu_{t}$ is the turbulent viscosity, it is a spatial coordinate function, depending on the flow state. Subscripts ( $i$ and $j$ ) represent the tensor notation $(i, j \in(1,2,3)), \mu_{i}, \mu_{j}$ are velocity components. $G_{k}$ is average velocity gradient production by the turbulent kinetic energy, $G_{b}$ is buoyancy term generation due to turbulence kinetic energy, $Y_{M}$ is contribution on behalf of compressible turbulent pulsation expansion, $\sigma_{k}, \sigma_{\varepsilon}$ are Prandtl numbers of turbulent kinetic energy $k$ and its dissipation rate $\varepsilon$, respectively. $C_{1 \varepsilon}, C_{2 \varepsilon}, C_{3 \varepsilon}$, are empirical constants.

Here $\mu_{t}, G_{k}, G_{b}, Y_{M}$ can be further expressed as Eqs. (3) - (6):

$$
\mu_{t}=\rho C_{u} \frac{k^{2}}{\varepsilon},
$$

where: $C_{\mu}=0.09$ is empirical constants.

$$
\begin{aligned}
G_{k} & =-\rho \overline{u_{i}^{\prime} u_{j}^{\prime}} \frac{\partial u_{i}}{\partial x_{j}}=\mu_{t}\left(\frac{\partial u_{i}}{\partial x_{j}}+\frac{\partial u_{j}}{\partial x_{i}}\right) \frac{\partial u_{i}}{\partial x_{j}}, \\
G_{b} & =-\frac{\partial \rho}{\rho} \frac{\mu_{t}}{P r_{t}} \frac{g_{i}}{\partial x_{i}} .
\end{aligned}
$$


where: $P r_{t}$ is turbulent Prrandtl number; $P r_{t}=0.85$ for this model; $g_{i}$ is variable for the acceleration of gravity in the $i$ direction.

$$
Y_{M}=2 \rho \varepsilon M_{t}^{2},
$$

where: $M_{t}$ is turbulent Mach number.

Because the high pressure gas is perpendicular to the gravity in the main direction of the gas film, therefore $C_{3 \varepsilon}=0$.

According to the recommended values of Launder et al and subsequent experiments, we set the model constants as: $\sigma_{k}=1.0, \sigma_{\varepsilon}=1.3, C_{1 \varepsilon}=1.44, C_{2 \varepsilon}=1.29$ [18].

BICGSTAB is a variant of the BiCG (Bi-Conjugate Gradient) method, it has faster and smoother convergence than the original $\mathrm{BiCG}$ as well as other variants such as the CGS (Conjugate Gradient Squared) method [19].

Finite element model after setted up, mesh division and boundary conditions are presented in Fig. 6.

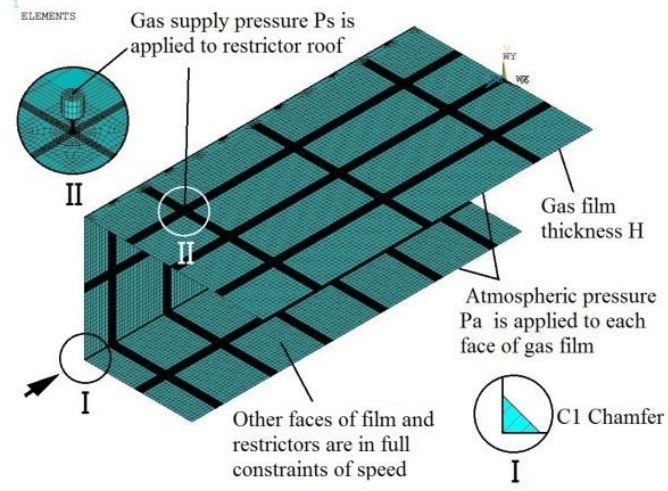

Fig. 6 Finite element model mesh generation and boundary conditions

The main working condition of this platform is long-time, low-speed micro-feed motion, the pressure field and flow field in stable state are analysed emphatically through the model. shown in Fig.7.

The air-floating platform design procedure chart as

\section{Orthogonal test design of air-floating platform structure}

In order to improve the platform performance, orthogonal test is applied to study the influence of different structure parameters on the guideway performance, which can provide theoretical reference for the optimum design of airfloating platform when structure of the platform has been set. The orthogonal test procedure as listed in Fig. 7.

4.1. The choice of orthogonal test parameters and test scheme

Loading capacity of air-floating guideway determines if the platform works stably in engraving process, and gas consumption determines production cost. Therefore, in the design, loading capacity and gas consumption are regarded as performance indicators and such parameters as thickness of gas film, width of guideway and gas supply pressure are tested on multiple levels to optimize the structure scheme.
In aerostatic guideway, the thickness of orifice compensation of gas film is generally between 0.01 and $0.05 \mathrm{~mm}$. In this design, the total length of $\mathrm{X}$ direction air-floating guideway is $4200 \mathrm{~mm}$ of which $3000 \mathrm{~mm}$ works effectively, flat face of guideway is within $0.003 \mathrm{~mm}$, parallelism of top and bottom of guideway face is within $0.005 \mathrm{~mm}$, verticality of side and top guideway face is within $0.004 \mathrm{~mm}$, and roughness of each guideway face is within $0.2 \mathrm{um}$, shown in Fig. 8. In order to ensure the platform work efficiently, the gas film should not be too thin, but not too thick to avoid the influence on the consumption and stiffness except in the technics requirement [20]. Therefore, in this study, parameters on three thickness of gas film with $0.020,0.025$ and $0.030 \mathrm{~mm}$ are chosen.

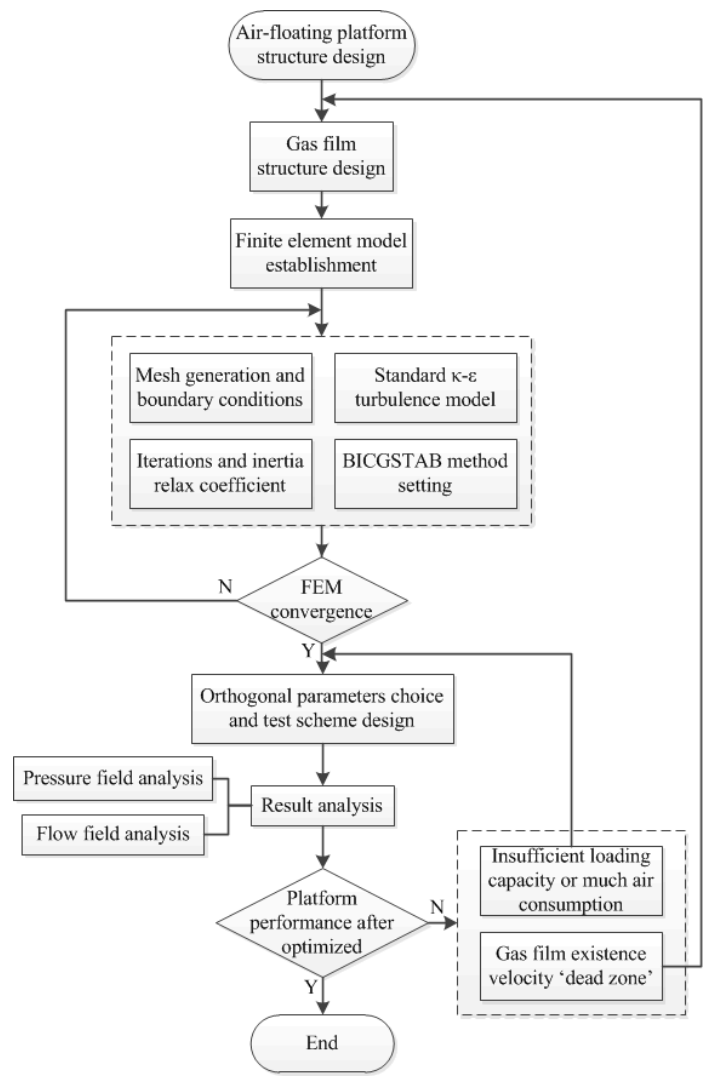

Fig. 7 Air-floating platform design procedure chart

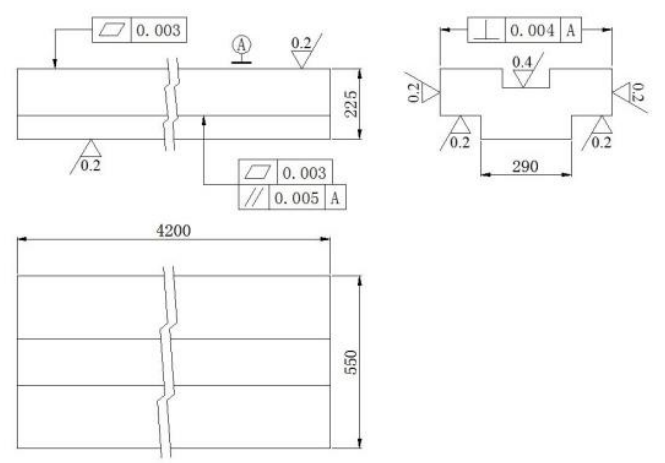

Fig. 8 Structure of $\mathrm{X}$ direction air-floating guideway

When the gas film thickness, air chamber, and pressure groove size are determined, the higher gas supply pressure is, the easier hammer vibration occurs. However, the pressure is too low to meet the requirements. So, in this test, three 
pressure levels of gas supply with $0.15,0.20$ and $0.25 \mathrm{MPa}$ are selected.

In order to make platform overcome whole system weight and eccentricity ratio approaches to zero, T-type guideway is usually designed for narrow bottom and wide top, with ratio of $B x / B s<1$. In order to ensure enough loading capacity on the vertical direction, three widths of guideway with 120 , 140 , and $160 \mathrm{~mm}$ are chosen respectively.

Test parameters about the platform structural optimum design are listed in Table 3.

Table 3

Orthogonal test factors and levels

\begin{tabular}{|c|c|c|c|}
\hline \multirow{2}{*}{ Levels } & \multicolumn{3}{|c|}{ Factors } \\
\cline { 2 - 4 } & $\begin{array}{c}\text { A-Gas film } \\
\text { thickness } H, \\
\mathrm{~mm}\end{array}$ & $\begin{array}{c}\text { B-Gas supply } \\
\text { pressure } P s, \\
\mathrm{MPa}\end{array}$ & $\begin{array}{c}\text { C-Width of bottom } \\
\text { guideway face } B x, \\
\text { mm }\end{array}$ \\
\hline 1 & 0.020 & 0.15 & 120 \\
\hline 2 & 0.025 & 0.20 & 140 \\
\hline 3 & 0.030 & 0.25 & 160 \\
\hline
\end{tabular}

In case of the interaction between factors ignored by three-factor and three-level orthogonal test, L9 $\left(3^{4}\right)$ orthogonal test table is chosen, and the blank column is used to estimate test error, shown in Table 4.

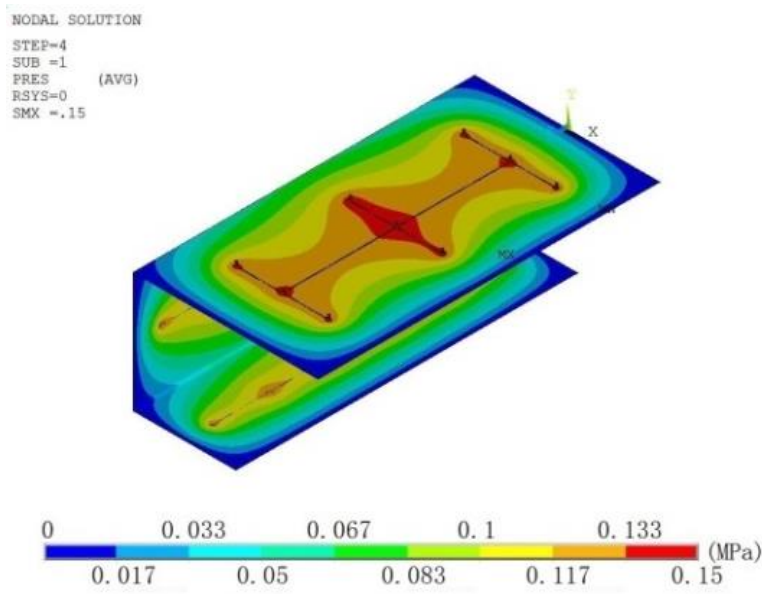

a) The pressure distribution of gas film

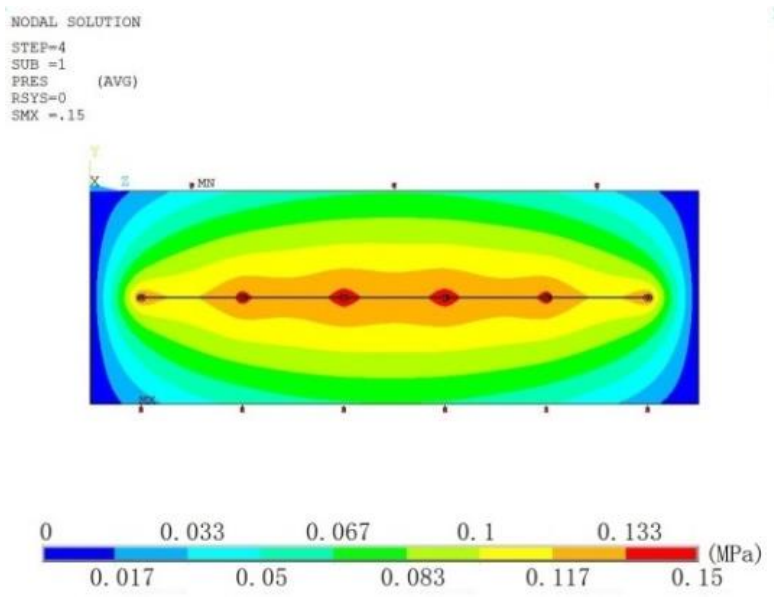

c) The pressure distribution of side gas film
Table 4

Orthogonal test scheme

\begin{tabular}{|c|c|c|c|c|}
\hline TN & $\begin{array}{c}\text { A-Gas film } \\
\text { thickness } \\
H, \mathrm{~mm}\end{array}$ & $\begin{array}{c}\text { B-Gas sup- } \\
\text { ply pressure } \\
P s, \mathrm{MPa}\end{array}$ & Error & $\begin{array}{c}\text { C-Width of bot- } \\
\text { tom guideway } \\
\text { face } B x, \mathrm{~mm}\end{array}$ \\
\hline 1 & $1(0.020)$ & $1(0.15)$ & 1 & $1(120)$ \\
\hline 2 & 1 & $2(0.20)$ & 2 & $2(140)$ \\
\hline 3 & 1 & $3(0.25)$ & 3 & $3(160)$ \\
\hline 4 & $2(0.025)$ & 1 & 2 & 3 \\
\hline 5 & 2 & 2 & 3 & 1 \\
\hline 6 & 2 & 3 & 1 & 2 \\
\hline 7 & $3(0.030)$ & 1 & 3 & 2 \\
\hline 8 & 3 & 2 & 1 & 3 \\
\hline 9 & 3 & 3 & 2 & 1 \\
\hline
\end{tabular}

4.2. Orthogonal test calculation

Based on Table 2, in total 9 finite element models are established and 4 steps are loaded to help gas compressibility convergence until inertia relaxation coefficient is $1.0 \times 10^{-10}$.

To implement the above ANSYS models, test 1 is chosen randomly and the pressure distribution of gas film is shown in Fig. 9.

According to simulation results, the distribution of

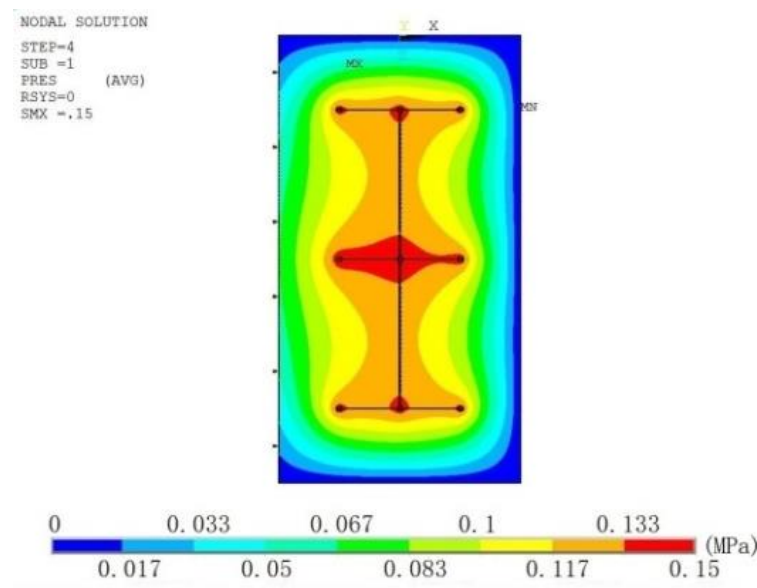

b) The pressure distribution of top gas film

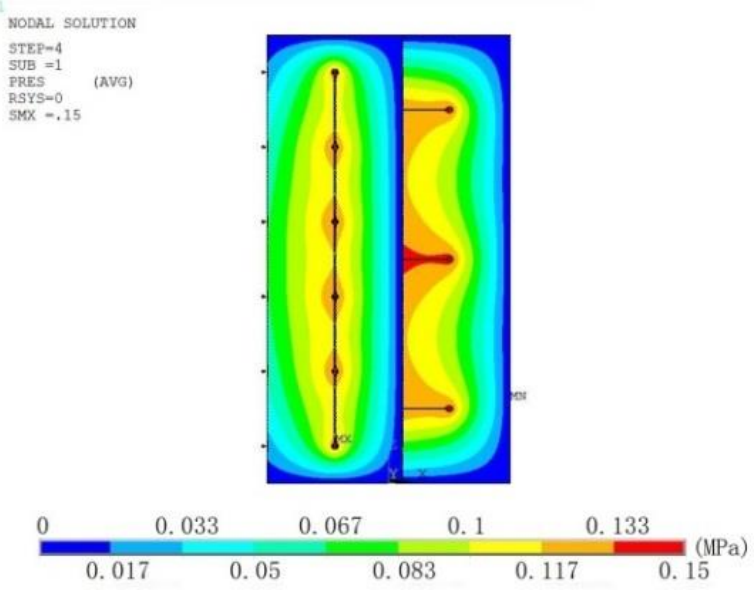

d) The pressure distribution of bottom gas film

Fig. 9 The pressure distribution of No.1 test

every gas film face is relatively independent, and the pressure is the highest around pressure-equalizing groove and low rapidly from the centre of gas film to each side. At the intersection of gas film faces, top and bottom gas films form higher pressure zone on one side of chamfer, and pressure distribution of side gas film is more symmetrical. 
The results from all tests show similar distribution in different pressure field of gas film, and loading capacity of gas film in every test is listed in Table 5.

As can be seen from Table 5, the loading capacity of guideway on the vertical direction means a difference in loading capacity between top gas film and bottom gas film. The test results also present that test 9 has the largest loading capacity, reaching $4895 \mathrm{~N}$, and test 4 has the smallest loading capacity, reaching $2486 \mathrm{~N}$ respectively. In each 3, 4, 8 test, the loading capacity of side gas film is the largest due to the gas is only exhausted from the front and the rear to have a higher utilization of guideway face and a greater pressure zone, although the side gas film is narrower than the bottom.

Table 5

The results of loading capacity analysis in orthogonal test

\begin{tabular}{|c|c|c|c|c|}
\hline TN & $\begin{array}{c}\text { Loading } \\
\text { capacity of } \\
\text { top gas } \\
\text { film } F s, \mathrm{~N}\end{array}$ & $\begin{array}{c}\text { Loading } \\
\text { capacity of } \\
\text { side gas } \\
\text { film } F c, \mathrm{~N}\end{array}$ & $\begin{array}{c}\text { Loading } \\
\text { capacity of } \\
\text { bottom gas } \\
\text { film } F x, \mathrm{~N}\end{array}$ & $\begin{array}{c}\text { Vertical } \\
\text { Loading ca- } \\
\text { pacity } \\
F=F s-F x, \mathrm{~N}\end{array}$ \\
\hline 1 & 7036 & 4481 & 3272 & 3763 \\
\hline 2 & 9378 & 5950 & 5114 & 4263 \\
\hline 3 & 11659 & 7375 & 7290 & 4368 \\
\hline 4 & 6401 & 4165 & 3915 & 2486 \\
\hline 5 & 8335 & 5492 & 3657 & 4679 \\
\hline 6 & 10153 & 6694 & 5297 & 4856 \\
\hline 7 & 5553 & 3769 & 2832 & 2721 \\
\hline 8 & 7057 & 4805 & 4179 & 2877 \\
\hline 9 & 8458 & 5825 & 3564 & 4895 \\
\hline
\end{tabular}

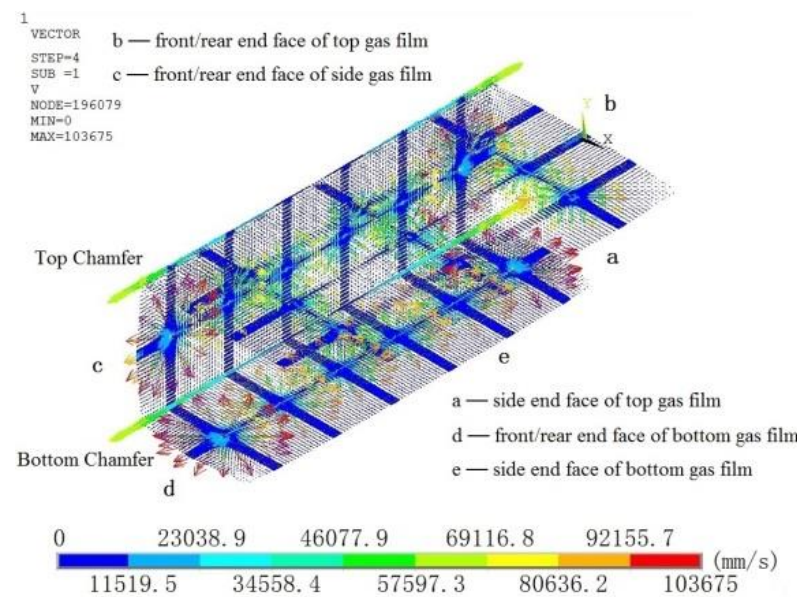

a) Flow field distribution of gas film
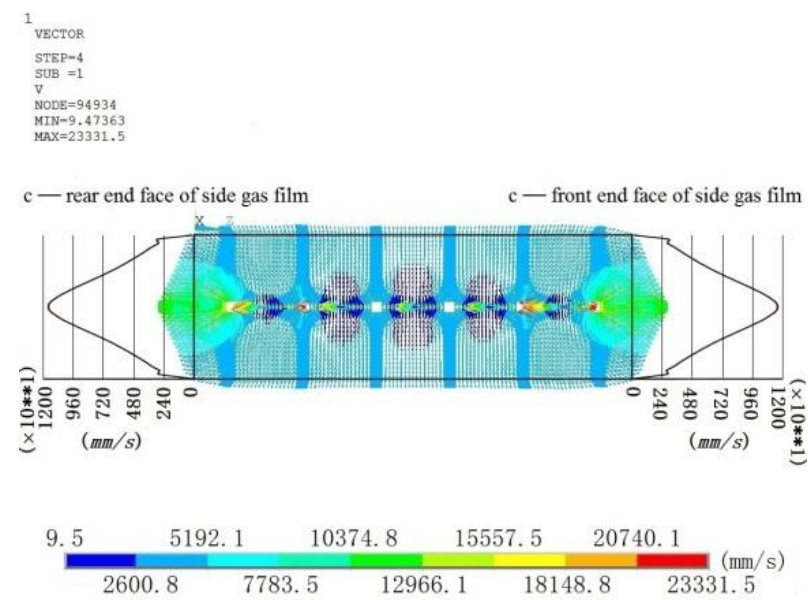

c) Flow field distribution of side gas film
In test 1 , the flow field distribution of each gas film is shown in Fig. 10.

Fig. 10, a, shows maximum flow velocity of all the gas film occurs around the exit of restrictors at the front and rear of each gas film, because of the gas with high speed after throttling dramatically changes direction when impinging bearing axletree surface, and restrictors near the ends are less affected by the pressure change. The flow velocity at both top and bottom chamfers is also higher, since one side at the chamfers of joint face has higher pressure and gas only exhausts through the front and rear at the chamfers leading to increasing velocity than other ends.

Besides, the flow velocity of the gas film changes greatly. In order to show the distribution of flow field more clearly, except the nodes at top and bottom chamfers and nearby the restrictors, flow velocity of nodes in each ends is fitted by higher order curve and then the distribution in Fig. 10, b-d shows that the maximum flow velocity of each ends occurs in the middle of the ends of gas film, where is maximum gas consumption too. At the corners of gas film, the flow velocity is close to zero caused by the decrease of pressure and velocity with gas flowing to the ends, and gas is exhausted through the nearby ends when arriving at the corners.

All the tests indicate that flow fields have similar distribution. Double integral is carried out for flow velocity curve of each end and gas film thickness, and the results show gas consumption in each test listed in Table 6.

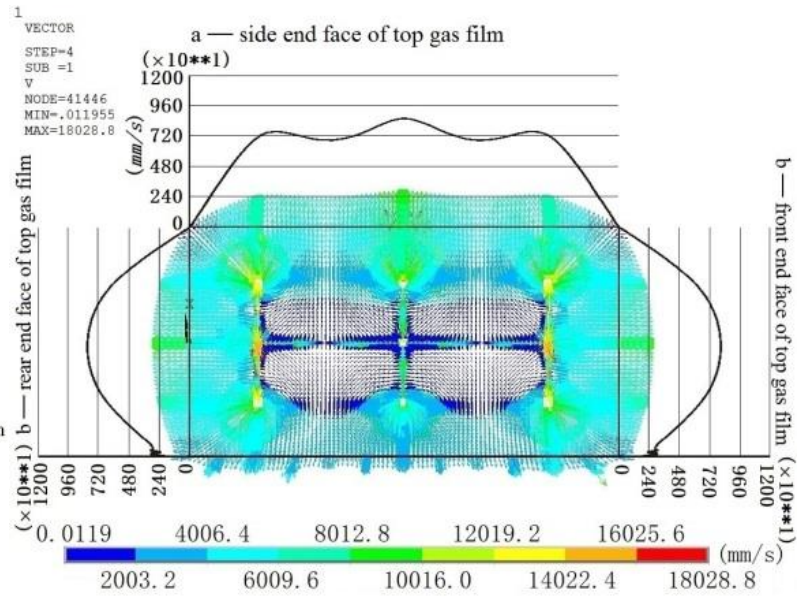

b) Flow field distribution of top gas film

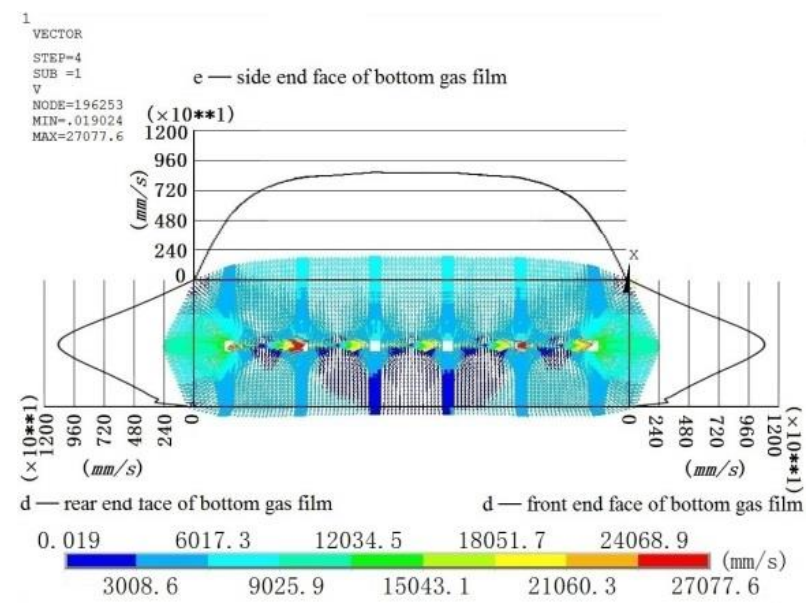

d) Flow field distribution of bottom gas film

Fig. 10 Flow field distribution of test 1 
As shown in Table 5, Table 6, test 9 shows the maximum loading capacity, and the gas consumption is also the highest, reaching $1342887 \mathrm{~mm}^{3} / \mathrm{s}$. Test 1 shows the minimum gas consumption, reaching $194818 \mathrm{~mm}^{3} / \mathrm{s}$. Although the ends of chamfers are small, the flow velocity is much higher than other ends, so the gas consumption at chamfers cannot be ignored.

Gas consumption in orthogonal test $\left(\mathrm{mm}^{3} / \mathrm{s}\right)$

\begin{tabular}{|c|c|c|c|c|c|c|c|c|}
\hline TN & Side a & Side $\mathrm{b} \times 2$ & Side $\mathrm{c} \times 2$ & Side $\mathrm{d} \times 2$ & Side e & $\begin{array}{c}\text { Top of } \\
\text { chamfer }\end{array}$ & $\begin{array}{c}\text { Bottom of } \\
\text { chamfer }\end{array}$ & Gas consumption \\
\hline 1 & 33620 & 32878 & 24976 & 19843 & 37878 & 22506 & 23117 & 194818 \\
\hline 2 & 48093 & 47076 & 35109 & 31899 & 46250 & 32215 & 31141 & 271783 \\
\hline 3 & 63381 & 62114 & 45655 & 46406 & 53101 & 42240 & 39064 & 351961 \\
\hline 4 & 87468 & 86527 & 64482 & 63178 & 72187 & 30324 & 27726 & 431892 \\
\hline 5 & 120700 & 119610 & 89073 & 64724 & 124800 & 41232 & 39312 & 599451 \\
\hline 6 & 154233 & 153205 & 113124 & 94769 & 139424 & 51444 & 47672 & 753871 \\
\hline 7 & 174309 & 175949 & 132514 & 106827 & 156900 & 34947 & 31587 & 813033 \\
\hline 8 & 232163 & 235450 & 176183 & 158796 & 185659 & 44919 & 40004 & 1073175 \\
\hline 9 & 289018 & 295334 & 223175 & 146904 & 285990 & 53332 & 49134 & 1342887 \\
\hline
\end{tabular}

\subsection{Design and analyses of orthogonal test}

Regarding the loading capacity and gas consumption as the critical indicators, the results of tests are analyzed through range analysis by considering the data in Table 5, Table 6 respectively.

The loading capacity is the basic requirement for platform stability. Practically the higher value is the better stability it can achieve. The range analysis of loading capacity is calculated in Table 7.

Table 7

Range analysis of loading capacity

\begin{tabular}{|c|c|c|c|c|c|}
\hline \multicolumn{2}{|c|}{ Indicator 1 } & $\mathrm{A}$ & $\mathrm{B}$ & Error & $\mathrm{C}$ \\
\hline \multirow{3}{*}{$\begin{array}{l}\text { Vertical } \\
\text { loading } \\
\text { capacity, } \\
\mathrm{N}\end{array}$} & $K_{F 1}$ & 12395 & 8971 & 11497 & 13337 \\
\cline { 2 - 7 } & $K_{F 2}$ & 12022 & 11820 & 11645 & 11841 \\
\cline { 2 - 6 } & $K_{F 3}$ & 10493 & 14119 & 11768 & 9732 \\
\cline { 2 - 6 } & $k_{F 1}$ & 4132 & 2990 & 3832 & 4446 \\
\cline { 2 - 6 } & $k_{F 3}$ & 3498 & 4706 & 3923 & 3947 \\
\hline \multicolumn{2}{|c|}{ Range $R$} & 634 & 1716 & 90 & 1202 \\
\hline $\begin{array}{c}\text { Primary and } \\
\text { secondary factors }\end{array}$ & \multicolumn{5}{|c}{$\mathrm{B} \rightarrow \mathrm{C} \rightarrow \mathrm{A}$} \\
\hline $\begin{array}{c}\text { Selecting } \\
\text { favorable project }\end{array}$ & \multicolumn{5}{|c}{$\mathrm{B} 3 \mathrm{C} 1 \mathrm{~A} 1$} \\
\hline
\end{tabular}

It can be observed from Table 7 factors of primary and secondary sequence of influencing loading capacity are gas supply pressure, bottom guideway width, gas film thickness. Based on the principle of most loading capacity, the favourable project is B3 C1 A1. Range of error is much smaller compared with other factors, which indicates that all the influencing factors are considered.

The gas consumption determines the production cost. Normally the lower value can greatly save money for the company. The range analysis of gas consumption is calculated and presented in Table 8 .

As can be seen from Table 8, the gas film thickness is the main factor of influencing gas consumption, and gas supply pressure following by. The bottom guideway width and range of error are both small, which indicates that bottom guideway has little influence on gas consumption. Based on the principle of least gas consumption, the favourable project is $\mathrm{A} 1 \mathrm{~B} 1 \mathrm{C} 2$.

As can be seen from Table 8, the gas film thickness is the main factor of influencing gas consumption, and gas supply pressure following by. The bottom guideway width and range of error are both small, which indicates that bottom guideway has little influence on gas consumption. Based on the principle of least gas consumption, the favourable project is $\mathrm{A} 1 \mathrm{~B} 1 \mathrm{C} 2$.

Table 8

Range analysis of gas consumption

\begin{tabular}{|c|c|c|c|c|c|}
\hline \multicolumn{2}{|c|}{ Indicator 2} & $\mathrm{~A}$ & $\mathrm{~B}$ & Error & $\mathrm{C}$ \\
\hline \multirow{3}{*}{$\begin{array}{c}\text { Gas } \\
\text { consum } \\
\text { ption, } \\
\mathrm{mm}^{3} / \mathrm{s}\end{array}$} & $K_{H 1}$ & 818562 & 1439743 & 2021863 & 2137157 \\
\cline { 2 - 6 } & $K_{H 2}$ & 1785214 & 1944409 & 2046563 & 1838687 \\
\cline { 2 - 6 } & $K_{H 3}$ & 3229095 & 2448719 & 1764445 & 1857028 \\
\cline { 2 - 6 } & $k_{H 1}$ & 272854 & 479914 & 673954 & 712386 \\
\cline { 2 - 6 } & $k_{H 3}$ & 595071 & 648136 & 682188 & 612896 \\
\hline \multicolumn{2}{|c|}{ Range $R$} & 803511 & 336325 & 94039 & 99490 \\
\hline $\begin{array}{c}\text { Primary and } \\
\text { secondary } \\
\text { factors }\end{array}$ \\
\hline $\begin{array}{c}\text { Selecting } \\
\text { favorable } \\
\text { project }\end{array}$ & $\mathrm{A} \rightarrow \mathrm{B} \rightarrow \mathrm{C}$ \\
\hline
\end{tabular}

According to the requirements of air-floating platform design, the above analysis results are summarized as following:

1. Based on the above analysis, A1 can be determined as film thickness.

2. It is contradictory that gas supply pressure is an influencing factor for both loading capacity and gas consumption. There is no cutting force during the platform works and the vertical loading capacity of single side on the $\mathrm{X}$ direction is about $3000 \mathrm{~N}$. It can be observed from three tests of A1, loading capacity is far beyond the requirement. Therefore, under the precondition to satisfy the loading capacity and according to the principle of least gas consumption, B1 is determined as gas supply pressure.

3. Considering the overturning moment on the $\mathrm{Y}$ direction when air-floating platform moves, $\mathrm{C} 2$ is determined as bottom guideway width to improve the gas film stiffness.

Overall, the favourable structure parameter of airfloating platform is A1 B1 C2, which means gas film thickness $H=0.02 \mathrm{~mm}$, air supply pressure $P s=0.15 \mathrm{MPa}$, bottom guideway width $B x=140 \mathrm{~mm}$. Due to the favourable project excluded in above tests, another test should be made, in which vertical loading capacity of the guideway is $3177 \mathrm{~N}$ and gas consumption is $191487 \mathrm{~mm}^{3} / \mathrm{s}$, herein lies the more 
loading capacity than that in test $4,7,8$, which can meet the loading requirements of single side of $3000 \mathrm{~N}$ and gas consumption is less than all other tests.

\section{Conclusions}

This study determines the structure of air-floating platform and optimizes the structural parameters by applying orthogonal tests. Conclusions from tests are drawn as following:

1. The distributions of pressure field and flow field for each gas film face are independent, the pressure around pressure groove is the highest and attenuates from gas film center to ends rapidly, maximum flow velocity occurs around restrictors at the front and rear of gas film and chamfers.

2. Gas supply pressure is the main factor influencing the loading capacity. The loading capacity and gas consumption increase with the pressure increasing. Gas film thickness is the main factor that influences the gas consumption. Both of the loading capacity decreases and gas consumption increases when the gas film thickness increases. Bottom guideway width is an important factor that can influence the loading capacity, but has little influence on gas consumption.

3. The optimized structure parameters are achieved, which are gas film thickness $H=0.02 \mathrm{~mm}$, gas supply pressure $P s=0.15 \mathrm{MPa}$, and bottom guideway width $B x=140 \mathrm{~mm}$, which can achieve vertical loading capacity of single side of $3177 \mathrm{~N}$ and gas consumption of $191487 \mathrm{~mm}^{3} / \mathrm{s}$. These structure parameters can efficiently satisfy the requirements of the loading capacity and longterm continuous work on long raster engraving air-floating platform.

\section{Acknowledgments}

The work is supported by the National Natural Science Foundation of China (Grant No. 51705228), Zhanjiang Science and Technology Project of China (Grant No. 2016B01012).

\section{References}

1. Amin-Shahidi, D.; Trumper, D. L. 2014. Design and control of a piezoelectric driven reticle assist device for prevention of reticle slip in lithography systems, Mechatronics 24(6): 562-571. https://doi.org/10.1016/j.mechatronics.2014.03.001.

2. Bisschops, T.; Vijfvinkel, J. 2001. Large ultra-precision motion feedthrough designs, Vacuum 60(1-2): 116165. https://doi.org/10.1016/S0042-207X(00)00371-7.

3. Teng, W.; Mu, H. H.; Zhou, Y. F. 2014. Key points of motion control for stage of lithography, Chinese Journal of Mechanical Engineering 50(8): 165-173 (in Chinese). https://doi.org/10.3901/JME.2014.08.165.

4. Chen, A. M.; Ma, P.; Gong, Z. 2009. Comparison of the loading capacity analysis of aerostatic guideway based on analytic method and finite element method, Lubrication Engineering 34(6): 43-48 (in Chinese). https://doi.org/10.3969/j.issn.0254-0150.2009.06.012.

5. Charki, A.; Diop, K.; Champmartin, S.; Ambari, A. 2013. Numerical simulation and experimental study of thrust air bearings with multiple orifices, International Journal of Mechanical Sciences 72(3): 28-38. https://doi.org/10.1016/j.ijmecsci.2013.03.006.

6. Du, J.; Zhang, G.; Liu, T.; To, S. 2014. Improvement on load performance of externally pressurized gas journal bearings by opening pressure-equalizing grooves, Tribology International 73(5): 156-166. https://doi.org/10.1016/j.triboint.2014.01.012.

7. Kassab, S. Z.; Noureldeen, E. M.; Shawky, M. A. 1997. Effects of operating conditions and supply hole diameter on the performance of a rectangular aerostatic bearing, Microelectronic Engineering 30(7): 533-545. https://doi.org/10.1016/S0301-679X(97)00001-7.

8. Yang Tao; Chen Gaige; Han Bin. et al. 2011. Threedimensional CFD simulation of flat pad aerostatic bearing with orifice array, Journal of System Simulation 23(12): 2709-2714. https://doi.org/10.1016/j.jengtecman.2010.12.006.

9. Horiuchi, T.; Suzuki, Y. 2013. Micro-fabrication of air-bearing grooves onto inner surfaces of fine copper pipes, Microelectronic Engineering 110(20): 422-426. https://doi.org/10.1016/j.mee.2013.03.020.

10. Qiu, Y. 2015. The static pressure renovation for the guide rail of the worktable, Heavy Machinery Science and Technology 2005(1): 23-26 (in Chinese). https://doi.org/10.3969/j.issn.1674-0963.2005.01.007.

11. Nakamura, T.; Yoshimoto, S. 1997. Static tilt characteristics of aerostatic rectangular double-pad thrust bearings with double row admissions, Tribology International 30(8): 605-611.

https://doi.org/10.1016/S0301-679X(97)00030-3.

12. Tao, J. S. 1996. Calculation of close double row orifice rectangular aerostatic slideways, Optics and Precision Engineering 4(2): 31-34. https://doi.org/10.1088/0256-307X/13/9/013.

13. Chen, G. G.; Yang, T.; Chen, L. et al. 2010. Simulation research on the relationship between orifice spacing and the characteristics of flat pad aerostatic bearing, Journal of Southwest University of Science and Technology 25(4): 62-67 (in Chinese). https://doi.org/10.3969/j.issn.1671-8755.2010.04.014.

14. Mo, D. Y.; Ma, P.; Gong, M. F. 2016. The effects of the gas film structure of air-bearing table of large stroke raster engraving on the gas film characteristics, Lubrication Engineering 41(3): 101-106 (in Chinese). https://doi.org/10.3969/j.issn.0254-0150.2016.03.020.

15. Gao, S.; Cheng, K.; Chen, S.; Ding, H. et al. 2015. CFD based investigation on influence of orifice chamber shapes for the design of aerostatic thrust bearings at ultra-high speed spindles, Tribology International 92: 211221. https://doi.org/10.1016/j.triboint.2015.06.020.

16. Zhou, Y.; Chen, X.; Chen, H. 2016. A hybrid approach to the numerical solution of air flow field in aerostatic thrust bearing, Tribology International 102: 444-453. https://doi.org/10.1016/j.triboint.2016.04.002.

17. Markatos, N. C. 1986. The mathematical modelling of turbulent flows, Applied Mathematical Modelling 10(3):190-220. https://doi.org/ 10.1016/0307-904x(86)90045-4.

18. Lee Jun Myung; Jeong Hoon; et al. 2016. Study on the turbulence model sensitivity for various cross-corrugated surfaces applied to matrix type heat exchanger, 
Journal of Mechanical Science and Technology 30(3): 1363-1375.

https://doi.org/10.1007/s12206-016-0243-1.

19. Wang, Y.; Li, S. J.; Meng, W. J. 2018. Thermo-mechanical strong coupling analysis on braking device of pipe belt conveyor, Journal of Mechanical Science and Technology 32(3): 1277-1285.

https://doi.org/10.1007/s12206-018-0232-7.

20. Nishio, U.; Somaya, K.; Yoshimoto, S. 2011. Numerical calculation and experimental verification of static and dynamic characteristics of aerostatic thrust bearings with small feedholes, Tribology International 44(12): 1790-1795.

https://doi.org/10.1016/j.triboint.2011.07.004.
D.Y. Mo, P. Ma, H. S. Lian, M. F. Gong

OPTIMAL DESIGN FOR THE STRUCTURE

PARAMETERS OF LONG RASTER

ENGRAVING AIR-FLOATING PLATFORM

S u m m a r y

Air-floating platform is the core component of long raster engraving system. In order to meet the demands of long raster engraving, this paper, proposes a three-dimension finite element model about gas film based on the validation of simulation model accuracy by test platform. We investigate the influence of the gas film thickness, air pressure and width of bottom guideway on the loaded capacity and air consumption by orthogonal test method. The best design scheme of air-floating platform structure is determined by range analysis method. The experiment results demonstrated that air film thickness, gas supply pressure, width of bottom guideway, the loading capacity of singlesided guideway and air consumption are $H=0.02 \mathrm{~mm}$, $P s=0.15 \mathrm{MPa}, B x=140 \mathrm{~mm}, 3177 \mathrm{~N}$ and $191487 \mathrm{~mm}^{3} / \mathrm{s}$, respectively. Hence, this scheme can greatly meet the requirements of the loading capacity and reduce air consumption of air-floating platform. It provides a basis for optimum structure design about air-floating platform.

Keywords: air-floating platform, finite element, orthogonal test, loading capacity, air consumption.

Received May 10, 2019

Accepted February 03, 2020 